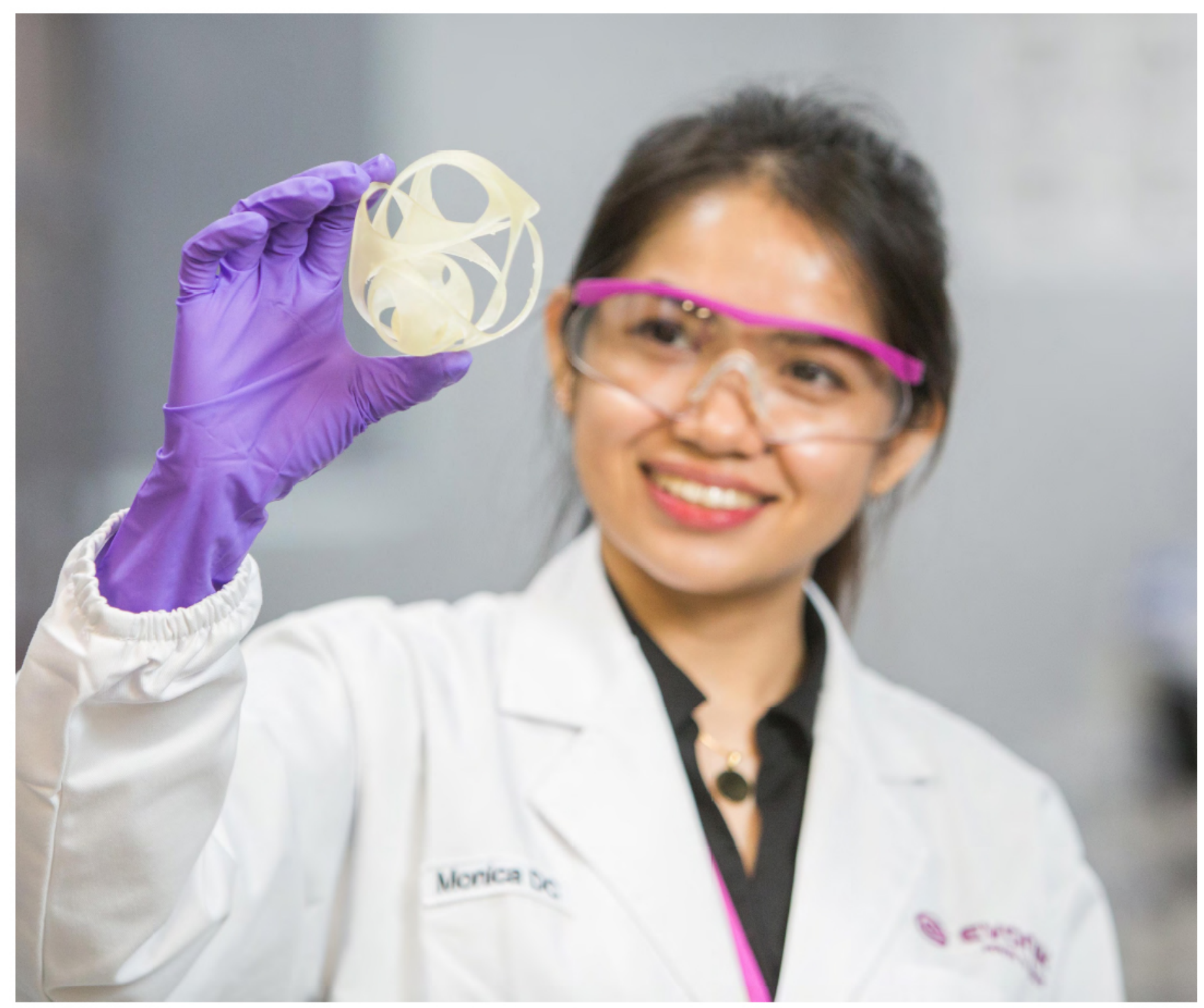

\title{
Pushing the boundaries
} of chemistry?

It takes \#HumanChemistry

Make your curiosity and talent as a chemist matter to the world with a specialty chemicals leader. Together, we combine cutting-edge science with engineering expertise to create solutions that answer real-world problems. Find out how our approach to technology creates more opportunities for growth, and see what chemistry can do for you at:

evonik.com/career 


\title{
Biopolymer Electrolyte Membranes (BioPEMs) for Sustainable Primary Redox Batteries
}

\author{
Perla Patricia Alday, Sandra Cerqueira Barros, Raquel Alves, José M. S. S. Esperança, \\ Marina Navarro-Segarra, Neus Sabaté, Maria Manuela Silva, and Juan Pablo Esquivel**
}

The proliferation of portable electronic devices has resulted in an increase of e-waste that is generated after their use. One of the most hazardous components in e-waste are batteries, due to their content of heavy metals and toxic chemicals. Fuel cells and redox flow batteries have been recognized as more sustainable alternatives to Li-based batteries for powering portable applications. Although they provide comparable energy and power densities, they still face some challenges because they rely on proton exchange membranes based on nonenvironmentally friendly, high-priced perfluorosulfonic acid copolymers that require energy-intense manufacturing and recycling procedures. In this work, eco-friendly and sustainable biopolymer electrolyte membranes (BioPEMs) are synthesized from biopolymers like chitosan, cellulose, and starch. These BioPEMs bring forth advantages in performance, sustainability, and cost. Additionally, they present good chemical and mechanical stability, high ionic conductivity in the same order of magnitude as Nafion membranes. Two alternatives of cellulose-chitosan based BioPEMs are successfully applied into primary redox batteries using benign eco-friendly redox chemistries, delivering open circuit voltages above $0.75 \mathrm{~V}$ and power output up to $2.5 \mathrm{~mW} \mathrm{~cm}^{-2}$. These results demonstrate BioPEMs capability to improve biodegradable batteries in sectors requiring a transient electrical energy, such as environmental monitoring, agriculture, or packaging.

\section{Introduction}

Fuel cells and redox flow batteries are electrochemical power sources where redox reactions take place at their electrodes as reactants flow separated by an ion conducting membrane. This electrolyte separator allows a selective transport of protons from anode to cathode and acts as an electron insulator material. ${ }^{[1-3]}$ The membrane is usually made from an ionomeric polymer, which must fulfill the following properties: i) high proton mobility, ii) reactant separation of the two half-cells, iii) low permeability to the redox reagents involved, i.e., avoid crossover, iv) adequate mechanical properties, allowing to obtain a membrane thickness of 10-250 $\mu \mathrm{m}, \mathrm{v}$ ) long lifetime, vi) low cost, and viii) the capability of fabrication into electrode/ membrane/electrode assemblies. ${ }^{[4]}$ Nowadays, the DuPont's Nafion membranes (perfluorosulfonic acid copolymer) and its derivate membranes dominate the market, particularly in polymer electrolyte membrane fuel cells (PEMFCs). ${ }^{[5]}$ However, Nafion has some serious draw-

Dr. P. P. Alday, M. Navarro-Segarra, Prof. N. Sabaté, Dr. J. P. Esquivel Instituto de Microelectrónica de Barcelona

IMB-CNM (CSIC)

C/ del Til.lers. Campus Universitat Autònoma de Barcelona (UAB)

Bellaterra 08193, Barcelona, Spain

E-mail: juanpablo.esquivel@csic.es

S. C. Barros, R. Alves, Prof. M. M. Silva

Centro de Química/Departamento de Química

Universidade do Minho

Campus de Gualtar, 4710-057 Braga, Portugal

J. M. S. S. Esperança

LAQV

REQUIMTE

Departamento de Química

Faculdade de Ciências e Tecnologia

Universidade Nova de Lisboa

2829-516 Caparica, Portugal

Prof. N. Sabaté

Catalan Institution for Research and Advanced Studies (ICREA)

Passeig Lluís Companys 23

08010 Barcelona, Spain

The ORCID identification number(s) for the author(s) of this article can be found under https://doi.org/10.1002/adsu.201900110.

DOI: 10.1002/adsu.201900110 backs; Nafion-based membranes are expensive because of their complex and high manufacturing process cost, they show low conductivity at reduced humidity levels and loss of mechanical stability at high temperature $\left(100{ }^{\circ} \mathrm{C}\right) \cdot{ }^{[6]}$ Moreover, with the growing commercialization of PEMFCs, the disposal of a large number of used Nafion membranes will become an important environmental issue. The recycling of this type of membranes is already under study, but its reuse does not seem to be straightforward, as the recycling procedures require high temperature and pressures. ${ }^{[7-10]}$

Recently, the aim to develop bio-solid polymer electrolytes (BioSPEs) based on natural polymers has arisen as alternative candidates to substitute synthetic polymer-based membranes due to their abundance, low-cost, and environmentally friendly nature. Such natural-based polymers include agar, ${ }^{[11,12]}$ gelatin, ${ }^{[13,14]}$ starch, ${ }^{[15]}$ cellulose, ${ }^{[16]}$ or chitosan..$^{[17-23]}$ In particular, chitosan $(\mathrm{CH})$ and its derivatives are been extensively investigated as some of the most attractive "green" materials for power sources applications due to their biodegradability, biocompatibility, nontoxicity, and low-cost. In this respect, Barros et al. reported an extensive characterization of hydrogel films based on the polysaccharides, $\mathrm{CH}$, and cellulose..$^{[17,23]}$ One of 
the recent applications of $\mathrm{CH}$ has focused on the synthesis of separators as alternative to conventional proton exchange membrane materials in fuel cells. ${ }^{[18]}$ In this area, Wan et al. reported the synthesis of $\mathrm{CH}$ membranes with different degrees of deacetylation and molecular weights for their future application in alkaline polymer electrolyte fuel cells. ${ }^{[24]}$ Some other membranes based on natural polymers, such as gelatin, have been doped with compounds such as europium triflate $\left(\mathrm{Eu}\left(\mathrm{CF}_{3} \mathrm{SO}_{3}\right)_{3}\right)$ to improve their electronic properties for applications in biotechnology. ${ }^{[13]}$ Starch biodegradable polymer electrolytes with high ionic conductivity were achieved by doping this biopolymer with lithium bis(trifluoromethanesulfonyl)imide (LiTFSI) and 1-allyl-3-methylimidazolium chloride ([Amim] Cl). ${ }^{[25]}$ Moreover, cellulose esters thermoreversible hydrogels like hydroxypropyl methylcellulose (HPMC), naturally derived from the most abundant naturally occurring biopolymer on earth, has been used to synthesize polymer films with ionic conductivity. The effect of doping these films with additives such as cadmium chloride $\left(\mathrm{CdCl}_{2}\right)$ has been reported. ${ }^{[26]}$ Rani and coworkers also reported solid polymer electrolyte films based on HPMC doped with sodium iodide $(\mathrm{NaI})$, selected due to its abundance and low cost compared to other inorganic salts. ${ }^{[27]}$

The research on biodegradable power sources has seen advances in novel approaches, which can potentially eliminate the end-of-life concerns posed by current primary battery technologies. Esquivel et al. reported a biotically degradable battery based on nontoxic, organic, abundant and inexpensive raw materials, and cost-efficient scalable manufacturing processes. This type of single-use battery, conceived for short-term applications, relies on the laminar flow of reactants in paper to separate anolyte and catholyte without any polymer electrolyte membrane. Indeed, the autonomy of these power sources would be significantly enhanced by the incorporation of a biopolymer electrolyte membrane (BioPEM) that meets the performance, biodegradability, and environmental sustainability requirements.

The objective of this work is to develop membranes based on biopolymers that represent an eco-friendly, sustainable, and naturally derived components of biodegradable portable power sources. ${ }^{[28]}$ The BioPEMs here presented have been synthesized from natural abundant polymers like chitosan, cellulose, and starch in order to ensure their eco-friendliness and sustainability. Additives such as glycerol, ionic liquids, and urea have been used to fulfill the essential electrolyte membrane properties. Their chemical and mechanical stability, ionic conductivity, and redox species crossover characterization is presented. Moreover, the best performing BioPEMs were evaluated in a primary redox battery using nontoxic, benign redox chemistries to validate their operation.

\section{Results and Discussion}

\subsection{Biopolymer Electrolyte Membranes Synthesis}

The synthesized BioPEMs must be compliant with certain requirements as chemical and mechanical stability, high ionic conductivity $\left(1 \times 10^{-5} \mathrm{~S} \mathrm{~cm}^{-1}\right.$, defined as the minimum threshold), present low crossover of redox species and favor having high power output in the device.
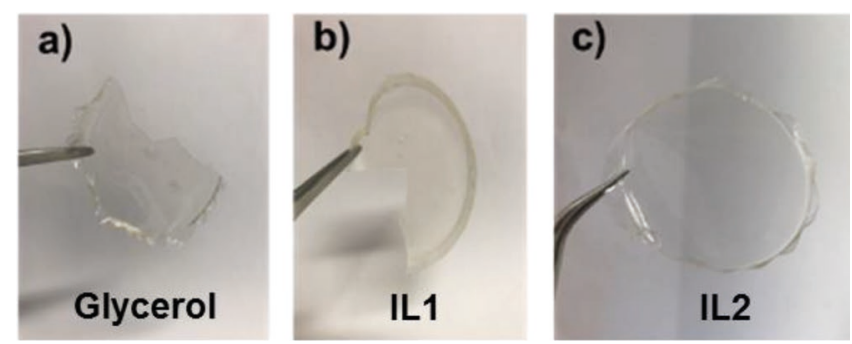

Figure 1. Photographs of the chitosan:cellulose-based BioPEMs: a) $\mathrm{CH}: \mathrm{HPMC}+$ gly, b) $\mathrm{CH}: \mathrm{HPMC}+\mathrm{ILI}$, and c) $\mathrm{CH}: \mathrm{HPMC}+\mathrm{IL} 2$.

The synthesis process of the BioPEMs must meet certain requirements in order to keep environmental sustainability. For this reason, a simple and affordable method was followed to synthesize two types of membranes, avoiding extreme temperatures and hazardous chemicals. The first type of the generated BioPEMs was a chitosan:cellulose-based in which the chitosan (CH) was mixed with HPMC to facilitate the gelation through large amounts of hydrophobic interactions. The mixture was then doped with different compounds to enhance the ionic conductivity. Thus, three different CH:HPMC BioPEMs were obtained: glycerol (gly), ionic liquid 1 (IL1), and ionic liquid 2 (IL2). Figure 1 shows the synthesized CH:HPMC BioPEMs samples. During the preparation of CH:HPMC+IL1, when the IL1 was added to the CH-HPMC solution, the mixture went from transparent to opaque. This can be explained due to the insolubility of $\mathrm{CH}$ in alkaline media, as a result of the basic $\mathrm{pH}$ upon addition of the ionic liquid IL1. The rest of the $\mathrm{CH}$ :HPMC BioPEMs resulted in mechanically robust, flexible, transparent, and completely amorphous films.

The second type of membranes synthesized were starchbased BioPEMs. As in the previous case, doping agents were added to the starch matrix obtaining: gly, IL1, IL2, and urea doped membranes. Figure 2 shows the starch-based films doped with glycerol and IL1 after their removal from the mold. The starch films were not as easily handled as the chitosan:cellulose-based BioPEMs, presenting a higher viscous consistency at room temperature. The films doped with urea and IL2 could not be removed from the Teflon molds, preserving a rubbery appearance attached to the mold and making impossible to perform the ionic conductivity tests.

The measurement of the BioPEMs thickness was performed using a digital micrometer (Mitutoyo 293 series, MDC-25P, Kanagawa, JP) and the obtaining values ranged between 65-244 and 154-348 $\mu \mathrm{m}$, for the CH:HPMC hydrogels and starch-based films, respectively. Due to the physical limitations that certain BioPEMs presented in this step, the ionic conductivity evaluation was carried out on the three chitosan:cellulose-based membranes (CH:HPMC+gly, CH:HPMC+IL1, and CH:HPMC+IL2)
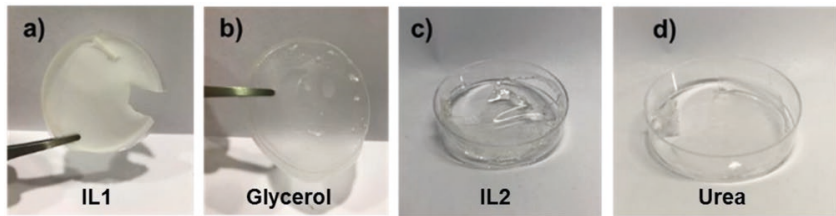

Figure 2. Photographs of the starch based BioPEMs: a) Starch+IL1, b) Starch+gly, c) Starch+IL2, and d) Starch+urea. 


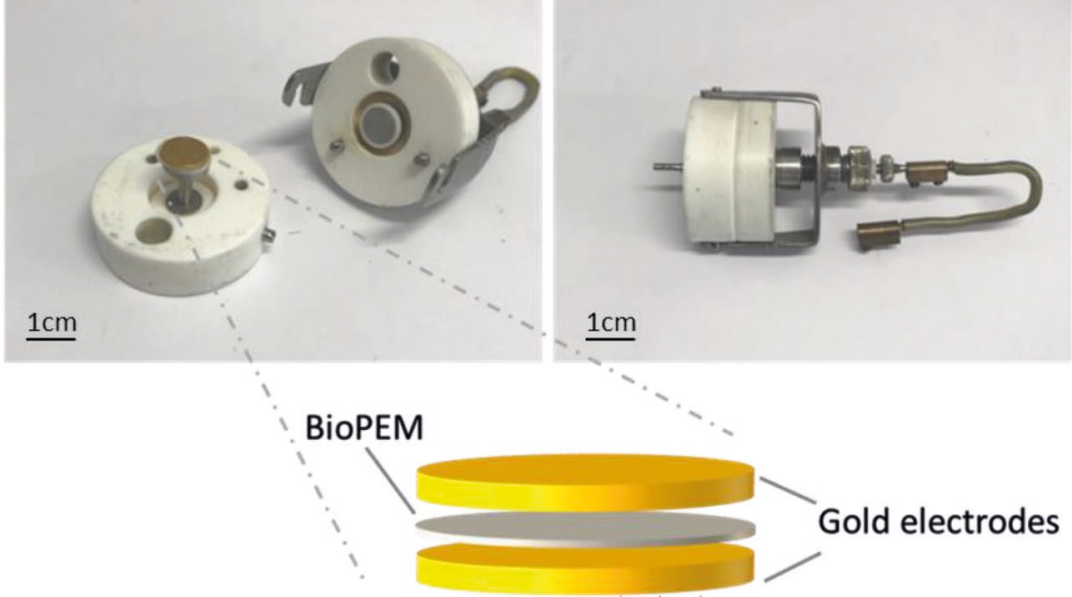

Figure 3. Symmetrical cell of gold-electrode/BioPEM/gold-electrode for electrochemical impedance spectroscopy evaluation.

and only on two of the starch-based membranes (Starch+IL1 and Starch+gly).

\subsection{BioPEMs Ionic Conductivity Characterization}

In order to assess the functionality of the BioPEMs as proton conducting electrolytes the total ionic conductivity of the synthesized materials was determined. For this purpose, the membranes were introduced between two ion-blocking gold electrodes, as shown in Figure 3. Electrochemical impedance spectroscopy technique was used to obtain the bulk resistance $R_{\mathrm{b}}$ during heating cycles between room temperature $\left(\approx 21^{\circ} \mathrm{C}\right)$ and $50{ }^{\circ} \mathrm{C}$, measured at $\approx 7^{\circ} \mathrm{C}$ intervals and over a frequency range between $65 \mathrm{kHz}$ and $500 \mathrm{mHz}$. The ionic conductivity $(\sigma)$ was determined according to the following equation

$\sigma_{\mathrm{i}}=\frac{d}{R_{\mathrm{b}} A}$

where $\sigma_{\mathrm{i}}$ is the ionic conductivity, $d$ is the thickness, $A$ is the electrode contact area, and $R_{\mathrm{b}}$ is the bulk resistance of the sample.

The measured values of ionic conductivity versus the inverse of the temperature are shown in Figure 4. The conductivity study of the BioPEMs shows that the addition of glycerol in comparison to the nonglycerol matrix results in an increase in conductivity. Glycerol is an organic molecule, which has high dielectric constant and low vapor pressure, and act as plasticizer. ${ }^{[29]}$ The role of the plasticizer is to dissociate the salt, which leads to the increase in the number of mobile ions and contributes to the conductivity enhancement. ${ }^{[30]}$ Other researchers have studied the influence of glycerol in polymer electrolytes based on gelatin and $\mathrm{LiBF}_{4}{ }^{[31]}$ They concluded that the increase of plasticizer promoted greater mobility of ions due to better solvation of the lithium ion. Alves et al. ${ }^{[32]}$ have reported the synthesis of gelatin as host polymer and magnesium triflate as salt, thin films were produced by varying the amount of glycerol concluding that the increased amount of glycerol results in an increase in conductivity. On the other hand, as the electrolyte is more malleable, it promotes a decrease in intra- and intermolecular interactions between the plasticizer and the matrix, induced by hydrogen bonding of $\mathrm{OH}^{-}$groups of glycerol with the chains of monosaccharides presented in chitosan and starch. Moreover, glycerol decrease the gel point due to their large affinity for water molecules and destroys the polymer water sheaths promoting the formation of the hydrophobic regions dehydrating the polymer. ${ }^{[33]}$ Their presence enhances the free volume of the polymer matrices and improves the molecular mobility of the macromolecules by destroying the hydrogen bond interactions between the polymer chains. ${ }^{[34]}$ Figure 4 evidences the conductivity enhancement produced by the addition of ionic liquids to a host matrix. The ILs addition also possibly stimulated a better separation of the $\mathrm{CH}$ and HPMC and starch chains, resulting in their more pronounced movements and consequent increase of ionic conductivity.

From the evaluated membranes, the highest ionic conductivity of $1.4 \times 10^{-2} \mathrm{~S} \mathrm{~cm}^{-1}$ at room temperature was obtained for the CH:HPMC+IL2 BioPEM, which stands at the same order of magnitude of the values reported for Nafion membranes ${ }^{[13]}$ $\left(10^{-2} \mathrm{~S} \mathrm{~cm}^{-1}\right)$. The membranes that ranked immediately below were the Starch+IL1 $\left(6.2 \times 10^{-4} \mathrm{~S} \mathrm{~cm}^{-1}\right)$ and CH:HPMC+gly $\left(4.9 \times 10^{-4} \mathrm{~S} \mathrm{~cm}^{-1}\right)$ BioPEMs with ionic conductivities in the same range value of Nafion NM-117 (tested in the same

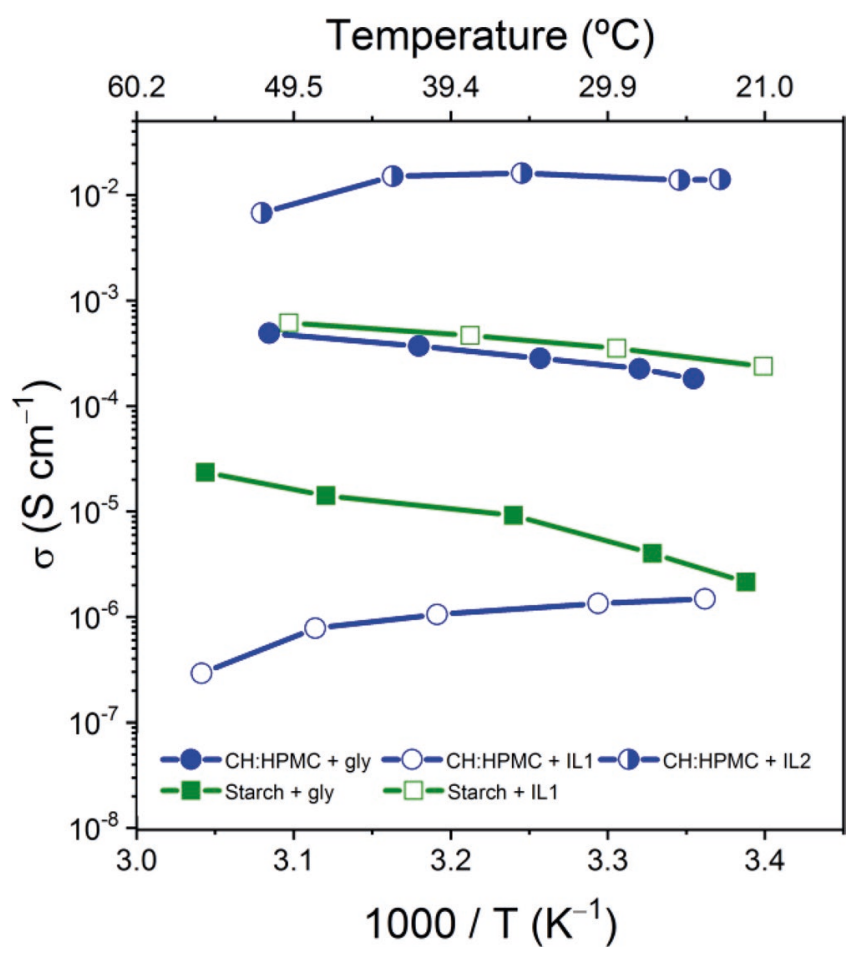

Figure 4. Ionic conductivity of the differently doped chitosan:cellulose and starch BioPEMs with temperature. 
conditions). Although the Starch+IL1 BioPEM exhibited one of the highest ionic conductivity values, the film is not very promising in terms mechanical properties. This membrane exhibits a brittle structure resulting in a material that does not meet the expected mechanical characteristics (flexibility) for a BioPEM. Finally, it can be seen that the levels of ionic conductivity evaluated for the starch+gly and starch+IL1 BioPEMs were below $10^{-4} \mathrm{~S} \mathrm{~cm}^{-1}$, which is inadequate for electrolyte membrane applications. ${ }^{[35]}$

The conductivities presented for these materials, similar to the lithium doped polymer electrolytes at room temperature, ${ }^{[19,36,37]}$ confirmed their correct operation as proton conductive polymer electrolytes. Based on these results, the $\mathrm{CH}: \mathrm{HPMC}$ matrix doped with glycerol or ionic liquid 2 presents the highest ionic conductivity together with appropriate mechanical characteristics to be used also as polymer electrolyte membranes. This capability will be explored in Sections 2.3 and 2.4.

\subsection{Crossover of Species through the BioPEMs}

In order to evaluate the performance of the synthesized materials as electrolyte membranes in redox batteries, the crossover of species across the two selected BioPEMs was first characterized. Thus, a dedicated setup was designed and four electroactive species were selected for the crossover test. Iron nitrate $\left(\mathrm{Fe}^{3+}\right)$ and p-benzoquinone (p-BQ) were chosen as cathodic species, whereas ascorbic acid (AA) and hydroquinone sulfonic acid $\left(\mathrm{H}_{2} \mathrm{BQ}\right)$ were selected as anodic ones. These species have been previously identified as benign and eco-friendly redox chemistries for biodegradable batteries. ${ }^{[28,38]}$

\subsubsection{Experimental Setup Design}

The strategy to evaluate the crossover of species through the BioPEMs materials and its performance in a BioPEM-cell was to monitor species concentration in time in a double half-cell setup. The half-cells were fabricated coupling different poly(methyl) methacrylate (PMMA) pieces with pressure sensitive adhesives (PSAs), see Figure 5a. Each half-cell was composed by a cubic compartment, which contained the corresponding solution and a space where a in-house fabricated screen-printed electrode (SPE, Figure 5b) was immersed in the solution. A cavity to fit the BioPEM was defined in the middle of both half-cells. The setup was finally assembled with four screws; Figure $5 \mathrm{c}$ shows a picture of the assembled setup. The transparency of the PMMA containers allows the visual inspection of the two compartments separated by the membrane. Compartment A was filled with a solution containing electrolyte and the electroactive species to be detected and compartment B contained only the corresponding electrolyte. The SPEs were used to measure the evolution of redox species concentrations in time (Figure $5 \mathrm{~d}$ ).

\subsubsection{Characterization of Redox Species Crossover}

The amount of species that migrate from compartment $\mathrm{A}$ to compartment B through the BioPEM (crossover) was quantified a)
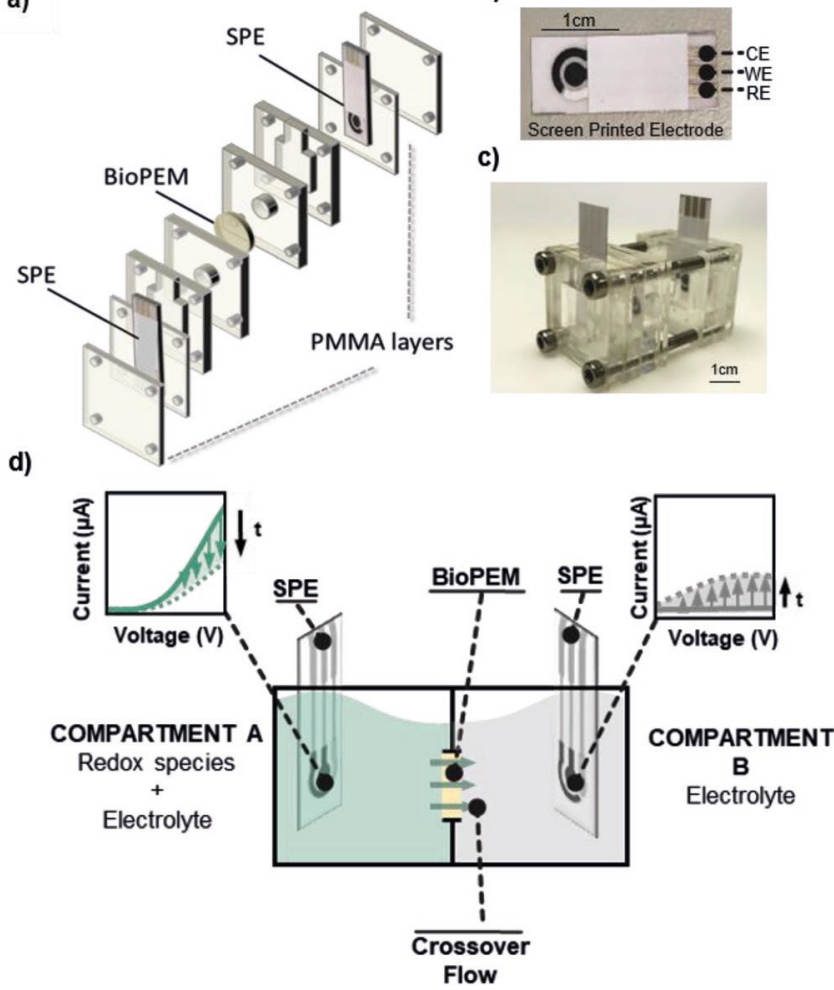

Figure 5. a) Exploded view of components of the characterization cell, b) Screen Printed Electrode (SPE), comprising the reference electrode (RE), the working electrode (WE), and the counter electrode (CE), c) picture of assembled cell, and d) schematic representation of the crossover analysis experiment.

by linear sweep voltammetry, which was performed on both compartments every $30 \mathrm{~min}$ during a period of $3 \mathrm{~h}$. This electrochemical method allows detecting the presence of the species and provides information of their concentration in solution. Figure 6 shows the onset potential region of the linear sweep voltammetry curves for the redox species evaluated in different characterization cells separated by the two BioPEMs: $\mathrm{CH}: \mathrm{HPMC}+\mathrm{gly}$ (on the left-side column) and $\mathrm{CH}: \mathrm{HPMC}+\mathrm{IL} 2$ (on the right-side column). Plots showing the oxidation currents of the anolytes $\left(\mathrm{H}_{2} \mathrm{BQ}\right.$ and $\left.\mathrm{AA}\right)$ are shown in Figure $6 \mathrm{a}-\mathrm{d}$, while the reduction currents of the catholytes ( $\mathrm{p}-\mathrm{BQ}$ and $\mathrm{Fe}^{3+}$ ) are shown in Figure $6 \mathrm{e}-\mathrm{h}$.

As it can be observed from the plots, there is a general decrease in the current output measured in compartment A over time. Conversely, an increase in the current signal recorded in compartment $\mathrm{B}$ confirms a migration of the electroactive species through the BioPEMs. In order to ease the performance comparison of the two tested BioPEMs with the different redox species, the variation of the current measured in compartment A has been normalized as a fraction of the current obtained in the first linear sweep of each test. This figure of merit has been labeled as Crossover percentage, and its evolution in time has been depicted in Figure 7. This figure shows that in the case of the anolytes, $\mathrm{H}_{2} \mathrm{BQ}$ and AA, lower levels of migration across the membrane $\mathrm{CH}: \mathrm{HPMC}+$ gly in a $3 \mathrm{~h}$ period of evaluation were registered, comparatively to 
CH:HPMC + gly

a)

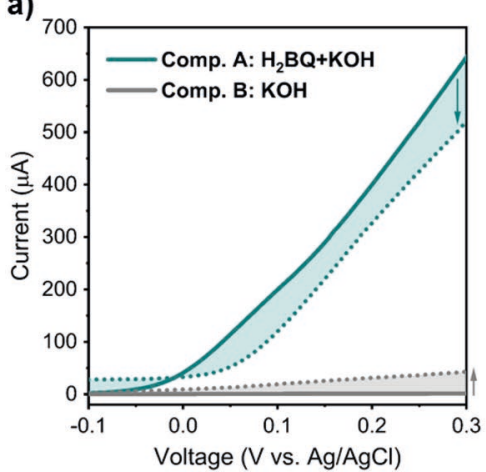

c)

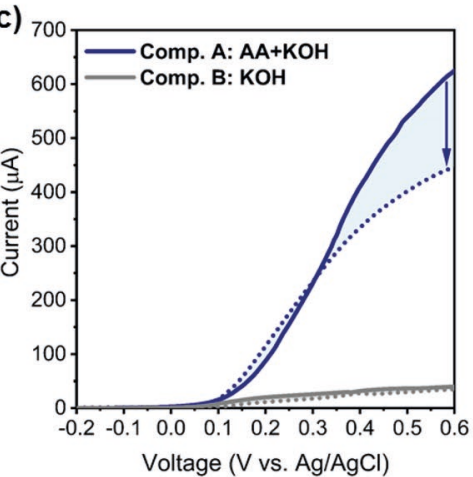

e)

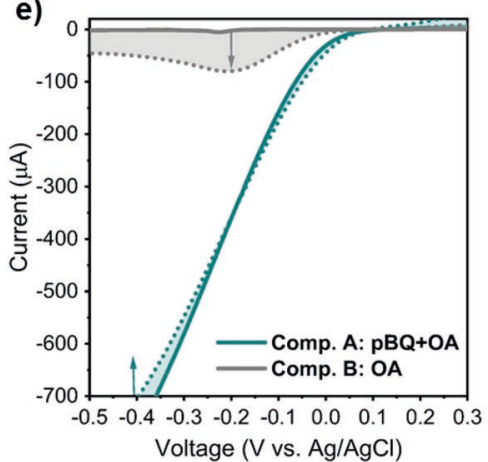

g)

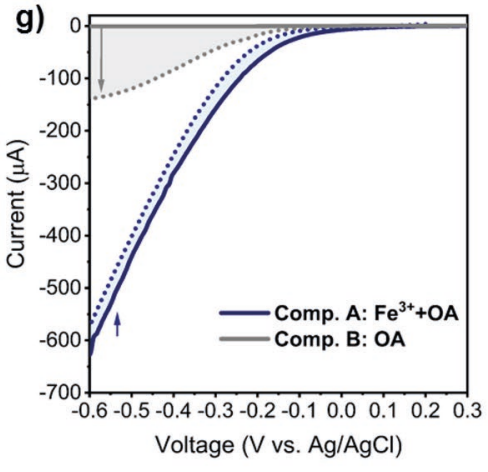

$\mathrm{CH}: \mathrm{HPMC}+\mathrm{IL} 2$

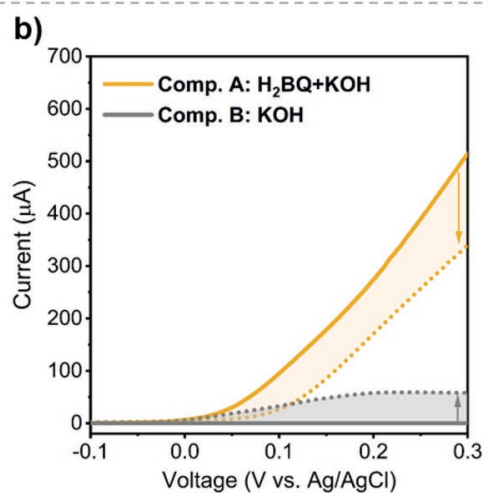

d)

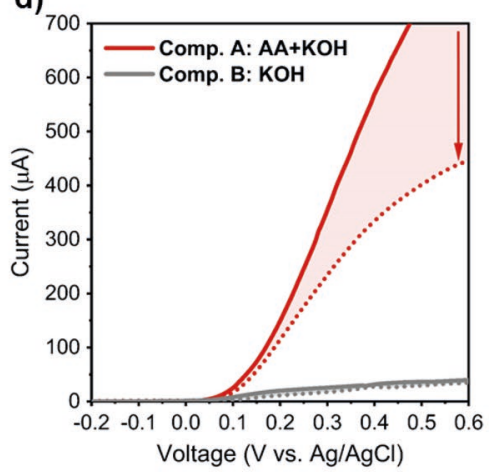

f)

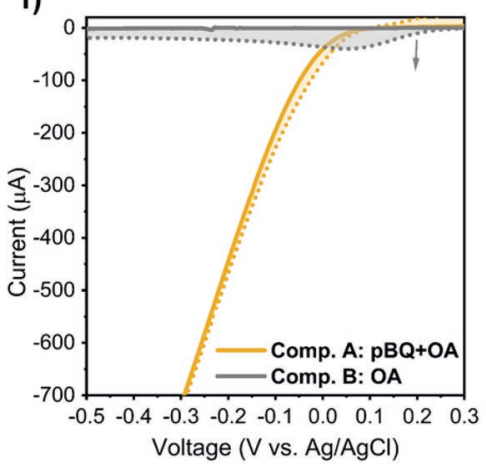

h)

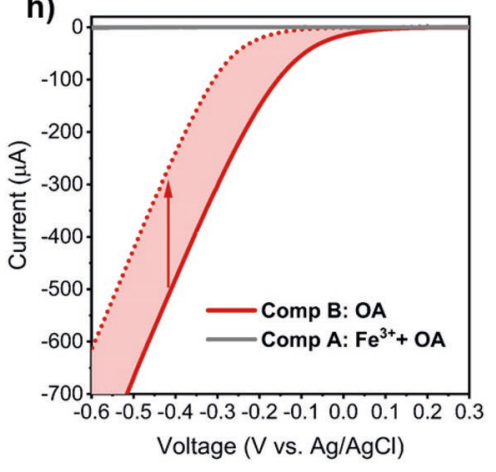

Figure 6. Linear sweep voltammetries measured from the compartments of the characterization cell tested with two BioPEMS and four redox species (solid line $t=0$; dashed line $t=3 \mathrm{~h}$ ). a) $\mathrm{H}_{2} \mathrm{BQ}, \mathrm{CH}: \mathrm{HPMC}+$ gly BioPEM, b) $\mathrm{H}_{2} \mathrm{BQ}, \mathrm{CH}: \mathrm{HPMC}+\mathrm{IL} 2$ BioPEM, c) AA, CH:HPMC+gly BioPEM, d) AA, CH:HPMC+IL2 BioPEM, e) p-BQ, CH:HPMC+gly BioPEM, f) p-BQ, $\mathrm{CH}: \mathrm{HPMC}+\mathrm{IL} 2 \mathrm{BioPEM}, \mathrm{g}) \mathrm{Fe}^{3+}, \mathrm{CH}: \mathrm{HPMC}+$ gly BioPEM, and h) $\mathrm{Fe}^{3+}, \mathrm{CH}: \mathrm{HPMC}+\mathrm{LL} 2$ BioPEM. membrane $\mathrm{CH}: \mathrm{HPMC}+\mathrm{IL} 2$. A similar trend was recorded for the $\mathrm{Fe}^{3+}$, with less crossover across the $\mathrm{CH}: \mathrm{HPMC}+$ gly BioPEM in comparison with the CH:HPMC+IL2 BioPEM. However, for the $\mathrm{pBQ}$ redox species, the crossover in both membranes was similar, showing a very low level of migration. The lowest crossover was therefore found by the p-BQ, a molecule that presents a neutral charge, while the charged molecules, such as the $\mathrm{H}_{2} \mathrm{BQ}, \mathrm{Fe}^{3+}$, and AA species, presented in general higher crossover through the membranes.

Since the evaluated BioPEMs are proton exchange membranes and present ion selectivity, they are not very permeable to nonpolar molecules. Both membranes showed that it is possible to hold more than $50 \%$ of the species in the reservoir for at least the first $3 \mathrm{~h}$ period of evaluation. The $\mathrm{CH}: \mathrm{HPMC}+\mathrm{IL} 2$ BioPEM is presented as the polymer electrolyte membrane with higher crossover, probably because the chlorides present in its structure (introduced via IL2) are being responsible for the transport of protons through the matrix.

\subsection{BioPEM-Battery Characterization}

The performance of the synthesized biopolymer electrolyte membranes was characterized in a primary redox battery configuration, as shown in Figure 8. Polarization curves were performed in complete cell configuration with the two best performing BioPEMs and using the redox chemistries previously characterized (all-quinone and $\mathrm{AA} / \mathrm{Fe}^{3+}$ ). ${ }^{[28,38]}$ These measurements were performed every $20 \mathrm{~min}$ for a $2 \mathrm{~h}$ period using the working electrodes of the SPEs as current collectors. The open circuit voltage of the cell was measured once the liquid species were added to both cell compartments and a steady values of $0.75 \pm 0.05 \mathrm{~V}$ in all-quinone and $0.90 \pm 0.05 \mathrm{~V}$ in $\mathrm{AA} / \mathrm{Fe}^{3+}$ were achieved. Figure 9 shows the $I-V$ curves obtained at a scan rate of $10 \mathrm{mV} \mathrm{s}^{-1}$. The inset in each plot shows the evolution in time of the maximum power density and the current density at the operating point of maximum power. As it can be seen, both BioPEMs showed good performance under the two evaluated redox chemistries. The battery using $\mathrm{CH}: \mathrm{HPMC}+$ gly BioPEM with $\mathrm{AA} / \mathrm{Fe}^{3+}$ chemistry recorded the highest maximum power density of $2.5 \mathrm{~mW} \mathrm{~cm}^{-2}$ and a stability of $91 \%$ over time. Batteries using the same BioPEM with the all-quinone chemistry presented a 


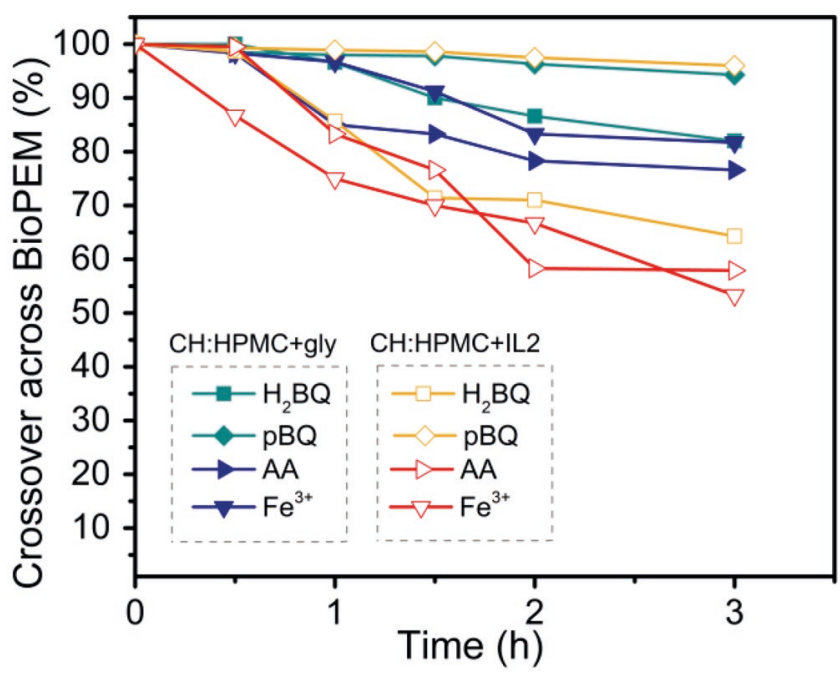

Figure 7. Crossover of the $\mathrm{CH}: \mathrm{HPMC}+$ gly and $\mathrm{CH}: \mathrm{HPMC}+\mathrm{IL} 2$ BioPEMs to the evaluated redox species: $\mathrm{H}_{2} \mathrm{BQ}, \mathrm{p}-\mathrm{BQ}, \mathrm{AA}$, and $\mathrm{Fe}^{3+}$.

power output of $1.5 \mathrm{~mW} \mathrm{~cm}{ }^{-2}$ and a very low decay in performance after the measured period of time. On the other hand, the batteries using CH:HPMC+IL2 generated a higher current and power values with the all-quinone chemistry, reaching $2.4 \mathrm{~mW} \mathrm{~cm}{ }^{-2}$. When this BioPEM was evaluated with $\mathrm{AA} / \mathrm{Fe}^{3+}$ chemistry, the maximum power density yielded $1.9 \mathrm{~mW} \mathrm{~cm}{ }^{-2}$ with a $95 \%$ stability.

\section{Conclusions}

This work presents the development of naturally derived polymer electrolyte membranes and their operation in primary passive redox batteries. The biopolymer membranes were individually characterized in terms of ionic conductivity, redox compounds crossover, and electrochemical performance. Since the addition of liquids and plasticizers, like glycerol, can induce the amorphization of the chitosan:cellulose matrix and increase its conductivity, two BioPEMs (CH:HPMC+gly and $\mathrm{CH}$ :HPMC+IL2) showed good ionic conductivity and low crossover of the redox species evaluated. It was observed that the CH:HPMC+IL2 membrane had the highest ionic

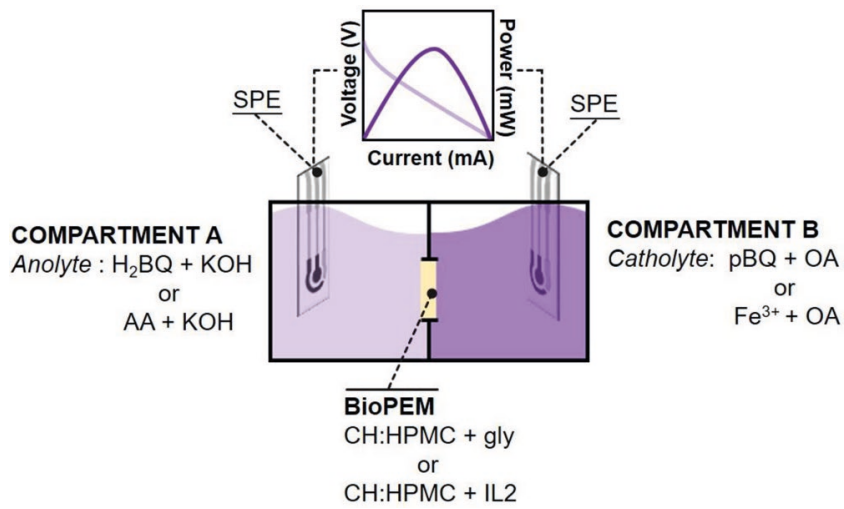

Figure 8. Schematic representation of the battery characterization set-up. conductivity, while the CH:HPMC+glycerol membrane was the one that allowed less migration of species overall. When evaluating BioPEMs in the redox battery, the membrane doped with glycerol provided the best performance using ascorbic acid and iron nitrate chemistry, with a maximum power density up to $2.5 \mathrm{~mW} \mathrm{~cm}{ }^{-2}$. The results show that these bioderived polymers as electrolyte membranes represent a promising alternative to replace conventional membranes based on perfluorosulfonic acid copolymers for sustainable electrochemical systems and biodegradable devices.

\section{Experimental Section}

Materials: The compounds used for the preparation of the biopolymer electrolyte membrane matrix consisted in the natural polymers chitosan (448 877, medium molecular weight, 75-85\% deacetylated,), and (hydroxypropyl) methyl cellulose (HPMC - H7509, viscosity 2600-5600 CP) Acetic acid (33 209, 99.8\%) was used for the chitosan dissolution. All products described herein were purchased to Sigma-Aldrich Company, Ltd (St. Louis, MO) and were used as received without further purification. For the other natural polymer matrix, starch (cationic, Brazil) was used as received. High-purity distilled water was used in all experiments. To improve the ionic conductivity of these polymeric solutions, several compounds were used to dope the $\mathrm{CH}: \mathrm{HPMC}$ matrix: glycerol (gly) (Himedia, 99.5\%), two different ionic liquids $\left[\mathrm{C}_{2} \mathrm{C}_{1} \mathrm{C}_{1} \mathrm{im}\right]$ [NTf2] (designed as IL1) and [[N111 (2OH)]Cl (referred as IL2) and urea (U5378, Sigma-Aldrich, Germany). $\left[\mathrm{C}_{2} \mathrm{C}_{1} \mathrm{C}_{1}\right.$ im] [NTf2] was acquired from loliTec with a stated purity higher than $99 \%$ and $[[\mathrm{N} 111(2 \mathrm{OH})] \mathrm{Cl}$ was purchased from Sigma-Aldrich with a purity better than $98 \%$. All ILs were dried under vacuum and moderate temperature for at least $48 \mathrm{~h}$. ${ }^{1} \mathrm{H}$ NMR and ${ }^{13} \mathrm{C}$ NMR were performed for all samples and confirmed the supplier indication. The redox compounds involved during this work consisted of hydroquinonesulfonic acid potassium salt $\left(\mathrm{H}_{2} \mathrm{BQ}, \mathrm{H} 18402\right)$, p-benzoquinone ( $\mathrm{p}-\mathrm{BQ}, \mathrm{B} 10358)$, oxalic acid dihydrate $\left(\mathrm{C}_{2} \mathrm{H}_{2} \mathrm{O}_{4}, \mathrm{O} 0376\right)$, potassium hydroxide ( $\mathrm{KOH}, \mathrm{P1767}), \mathrm{AA}$ (A92902) (all from SigmaAldrich, St Louis, MO), and iron nitrate $\left(\mathrm{Fe}\left(\mathrm{NO}_{3}\right)_{3}, 103\right.$ 883) acquired to Merck KGaA (Darmstadt, Germany). For the experiments assays, redox electrolytes solutions were prepared: $0.1 \mathrm{M}$ of $\mathrm{H}_{2} \mathrm{BQ}$ and $0.1 \mathrm{M}$ of $\mathrm{AA}$ in $1.0 \mathrm{M}$ of $\mathrm{KOH}$ and $0.1 \mathrm{M}$ of pBQ and $0.5 \mathrm{M}$ of Fe $\mathrm{Fe}^{3+}$ in $0.5 \mathrm{M}$ of $\mathrm{C}_{2} \mathrm{H}_{2} \mathrm{O}_{4}$.

Chitosan-Cellulose-Based Electrolytes Preparation: The synthesis of the chitosan and (hydroxypropyl) methyl cellulose (CH:HPMC) matrix was performed by solvent casting. First, the stock solutions of the natural polymers (2 wt \%) were obtained to subsequently prepare the different BioPEMs. Briefly, $1 \mathrm{~g}$ of $\mathrm{CH}$ was dissolved in $50 \mathrm{~mL}$ of aqueous acetic acid (1 wt\%) and $1 \mathrm{~g}$ of HPMC $50 \mathrm{~mL}$ ultrapure water. These polymeric mixtures were stirred overnight at room temperature until a homogeneous and viscous solution was formed. All products described herein were purchased to Sigma-Aldrich Company, Ltd (St. Louis, $\mathrm{MO})$ and were used as received without further purification. The $\mathrm{pH}$ of the HPMC: $\mathrm{CH}(75: 25)$ was around 3.75-4.75.[17] For the biopolymer electrolyte membranes, $\mathrm{CH}$ and $\mathrm{HPMC}$ solutions were mixed together in 25:75 ratio to form the base matrix. Three polymeric solutions of $10 \mathrm{~mL}$ were prepared by mixing $2.5 \mathrm{~mL}$ of $\mathrm{CH}$ and $7.5 \mathrm{~mL}$ of HPMC. To improve the ionic conductivity of these polymeric solutions, several compounds were used to dope the $\mathrm{CH}: \mathrm{HPMC}$ matrix: glycerol (gly) (Himedia, 99.5\%) and two different ionic liquids [ $\mathrm{C}_{2} \mathrm{mim}$ ] [NTf2] (designed as IL1) and $[[\mathrm{N} 111(2 \mathrm{OH})] \mathrm{Cl}$ (referred as IL2). Therefore, $0.2 \mathrm{~g}$ of glycerol (added as plasticizer), IL1 and IL2 were added to each solution in order to get different doped polymer electrolytes. The resulting polymeric solutions were stirred for $2 \mathrm{~h}$ at room temperature. After this period the solutions were cast into $5.5 \mathrm{~mm}$ diameter Petri dishes (BP50-01, Gosselin, Hazebrouck, FR) and left to dry in an incubator (Thermo Fisher Scientific, MA) for $96 \mathrm{~h}$ at $25^{\circ} \mathrm{C}$.

Starch-Based Electrolytes Preparation: In order to obtain polymeric membranes from another natural source, starch-based BioPEMs 


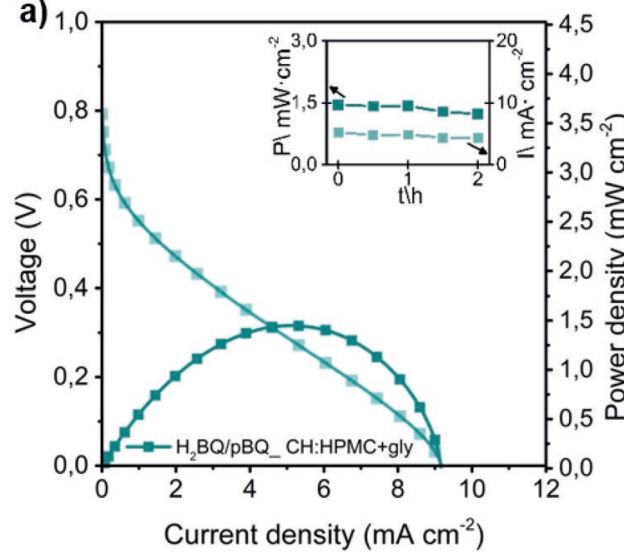

c)

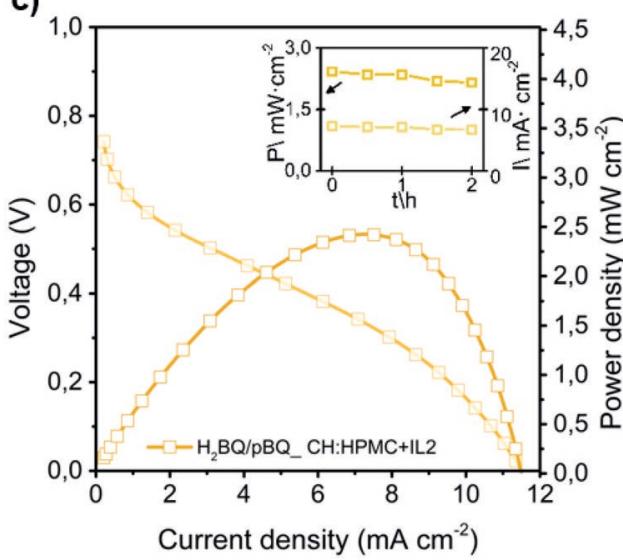

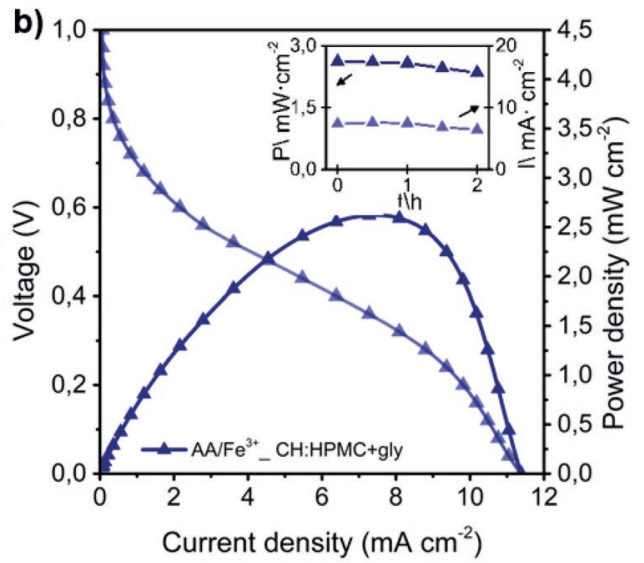

d)

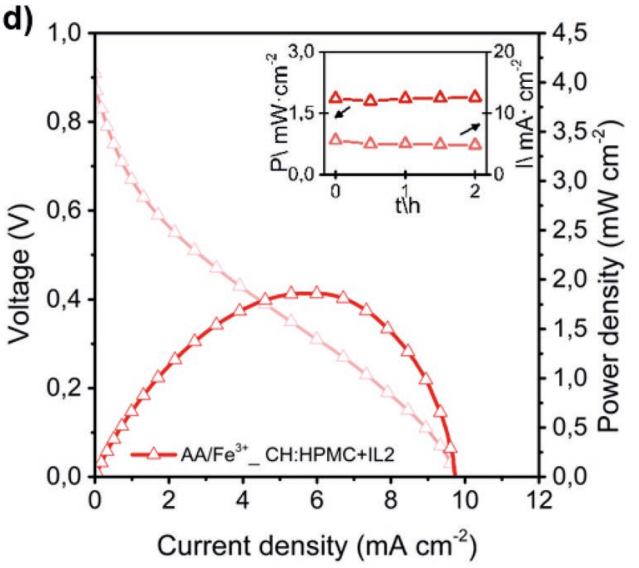

Figure 9. Polarization curves of redox batteries with two different BioPEMs and two redox chemistries. a) $\mathrm{CH}: \mathrm{HPMC}+\mathrm{gly} B i o P E M$ using $\mathrm{H}_{2} \mathrm{BQ} / \mathrm{pBQ}$, b) $\mathrm{CH}: \mathrm{HPMC}+$ gly BioPEM using AA/Fe ${ }^{3+}$, c) $\mathrm{CH}: \mathrm{HPMC}+\mathrm{IL} 2$ BioPEM using $\mathrm{H}_{2} \mathrm{BQ} / \mathrm{pBQ}$, and d) $\mathrm{CH}: \mathrm{HPMC}+\mathrm{IL} 2 \mathrm{BioPEM}$ using AA/Fe ${ }^{3+}$.

were prepared. Two main starch matrixes were synthesized and were doped with different compounds to increase their ionic conductivity. On the one hand, glycerol was used as plasticizer and the samples were doped with IL1 and IL2 and a third one was prepared only with the addition of glycerol. On the other hand, a second starch-based BioPEM was prepared with the addition of urea (U5378, SigmaAldrich, Germany) as a plasticizer and was doped with IL2. The samples were prepared by dispersion of $1.2 \mathrm{~g}$ of starch in $30 \mathrm{~mL}$ of ultrapure water (Mili-Q) and stirred for $2 \mathrm{~h}$ at $70-80{ }^{\circ} \mathrm{C}$, until a homogeneous and viscous solution was formed. An extra water sample was located in the stirring plate as a temperature control. The solution was brought to room temperature. After this, $0.6 \mathrm{~g}$ of glycerol were added the starch-gly BioPEMs and doped with $0.4 \mathrm{~g}$ of IL 1 and IL2. On the other side, for urea samples, $0.6 \mathrm{~g}$ of urea as matrix was added and was doped with $0.4 \mathrm{~g}$ of IL2. The resulting solutions were cast into Teflon dishes and dried for $72 \mathrm{~h}$ at $25^{\circ} \mathrm{C}$. After this time, it was observed that samples needed more drying time, therefore sample A doped with ILI was put it overnight at $40{ }^{\circ} \mathrm{C}$ to get a dried film. However, starch-BioPEM with urea and IL2 were left for $7 \mathrm{~d}$ at $25{ }^{\circ} \mathrm{C}$ and were not able to get a working film.

BioPEMs Ionic Conductivity Characterization: The total ionic conductivity of the polymer electrolytes was determined by introducing the membranes between two ion-blocking gold electrodes (Goodfellow, $>99.95 \%, \varnothing 10 \mathrm{~mm}$, UK). The symmetrical cell composed of Gold electrode/BioPEM/Gold electrode was assembled in a custom-made constant volume support and installed in a Büchi glass tube oven (Büchi, TO51) with a K-type thermocouple localized close to electrolyte disk to measure the sample temperature. An Autolab potentiostat (Metrohm, Eco Chemie, PGSTAT-12, NL) was used to obtain bulk ionic conductivities, during heating cycles between room temperature $\left(\approx 21{ }^{\circ} \mathrm{C}\right)$ and $50^{\circ} \mathrm{C}$, measured at $\approx 7^{\circ} \mathrm{C}$ intervals and over a frequency range between $65 \mathrm{kHz}$ and $500 \mathrm{mHz}$.

BioPEM Performance Characterization Setup: Once the BioPEMs were synthesized, the next step was to evaluate and validate the crossover of the redox species across the membranes and the performance of a BioPEM-battery. For this purpose, a two half cells setup that allowed the incorporation of the BioPEM was fabricated using poly(methyl methacrylate) (Plexiglas, Evonik Performance Materials $\mathrm{GmbH}$, Darmstadt, Germany) layers assembled using PSAs (Adhesives Research, Glen Rock, PA). The device components were designed in a CAD program (CorelDRAW, Corel, Ottawa, ON, Canada). All the components were cut using a $\mathrm{CO}_{2}$ laser cutter (Mini 24, Epilog Laser, Golden, (C) and manually assembled layer by layer using screws that allow the pieces to be firmly joined. For this purpose, in-house fabricated screen printed (SPEs) were employed.

Screen Printed Electrodes Fabrication: ${ }^{[39]}$ The SPE consisted of $\mathrm{Ag} / \mathrm{AgCl}$ ink as the reference electrode (RE) and a carbon ink for the counter (CE) and working (WE) electrode with $0.07 \mathrm{~cm}^{2}$ of area. A semiautomatic screen-printing machine was used for the fabrication of screen-printed electrodes. Initially, three tracks of silver (Ink code: LOCTITE ECI 1011, Henkel, Dusseldorf, Germany) were screen-printed on the polyethylene terephthalate (PET) substrate, following this a layer of carbon ink (ink code: C2030519P4, Gwent Electronic Materials Ltd., Pontypool, Wales) was screen-printed over the silver ink, in order to define the circular working electrode the area of $0.70 \mathrm{~cm}^{2}$ and the counter electrode. Finally, a silver/silver chloride ink (ink code: C2130429D3, GEM Ltd.) was printed to fabricate the reference electrode. Between each printing step, the inks were cured in an oven following the supplier instructions. 
Characterization of Redox Species Crossover: The crossover of the species through the two selected BioPEMs was evaluated toward the four redox compounds: $\mathrm{H}_{2} \mathrm{BQ}, \mathrm{p}-\mathrm{BQ}, \mathrm{AA}$, and $\mathrm{Fe}^{3+}$. Permeability was calculated by carrying out linear sweep voltammetries (LSV) in potentiodynamic mode at a scanning speed of $10 \mathrm{mV} \mathrm{s}^{-1}$, placing in one compartment the redox specie and its electrolyte and in the other compartment only the correspondent electrolyte. The LSV were measured in each compartment over time. Based on the voltammetries, the maximum current generated in each cell compartment was calculated. In this way, the voltamograms of each half-cell were obtained, the current in the first measurement was set as a reference and the percentage of this current from the subsequent measurements was calculated as a figure of merit of the migration of redox compounds.

Electrochemical Characterization of BioPEM Battery: In order to test the synthesized electrolyte membranes in the battery cell system, polarization curves were performed in complete cells with the incorporation of the membranes, $\mathrm{CH}: \mathrm{HPMC}+$ gly and $\mathrm{CH}: \mathrm{HPMC}+\mathrm{IL} 2$ BioPEMs in the PMMA setup. The potential was swept from open circuit potential to zero volts, at a scan rate of $10 \mathrm{mV} \mathrm{s}^{-1}$. All electrochemical characterization curves were recorded with a potentiostat Dropsens $\mu$ Stat 400 (Dropsens, Oviedo, Spain).

\section{Acknowledgements}

P.P.A. acknowledges support from CONACyT through a scholarship to pursue postgraduate studies. N.S. thanks financial support received from ERC Consolidator Grant (SUPERCELL - GA.648518). The authors thank the FCT(Fundação para a Ciência e Tecnologia) for financial support under the framework of Strategic Funding Grant Nos. UID/ QUI/0686/2019 and UID/QUI/50006/2019.

\section{Conflict of Interest}

The authors declare no conflict of interest.

\section{Keywords}

biodegradable batteries, biopolymer electrolyte membranes, circular economy, green electronics, redox flow batteries

Received: October 9, 2019

Revised: November 29, 2019

Published online: December 20, 2019

[1] M. Winter, R. J. Brodd, Chem. Rev. 2004, 104, 4245.

[2] J. Walkowiak-Kulikowska, J. Wolska, H. Koroniak, Phys. Sci. Rev. 2017, 2, 1.

[3] A. Kirubakaran, S. Jain, R. K. Nema, Renewable Sustainable Energy Rev. 2009, 13, 2430.

[4] S. Cheng, H. Liu, B. E. Logan, Environ. Sci. Technol. 2006, 40, 364.

[5] M. A. R. Sadiq Al-Baghdadi, Int. J. Energy Environ. 2012, 3, 485.

[6] N. Cele, S. Sinha Ray, Macromol. Mater. Eng. 2009, 294, 719.

[7] H. F. Xu, X. Wang, Z. G. Shao, I. M. Hsing, J. Appl. Electrochem. 2002, 32, 1337.

[8] C. Handley, N. P. Brandon, R. Van Der Vorst, J. Power Sources 2002, 106, 344.
[9] G. M. A. Ribeiro, M. Conde, J. Carvalho, L. C. Rodrigues, R. D. Carneiro-Alves, R. A. S. Ferreira, A. Pawlicka, L. D. Carlos, M. M. Silva, Mol. Cryst. Liq. Cryst. 2012, 562, 147.

[10] M. J. Parnian, S. Rowshanzamir, J. Alipour Moghaddam, Mater. Sci. Energy Technol. 2018, 1, 146.

[11] E. Raphael, C. O. Avellaneda, B. Manzolli, A. Pawlicka, Electrochim. Acta 2010, 55, 1455.

[12] E. Lima, E. Raphael, F. Sentanin, L. C. Rodrigues, R. A. S. Ferreira, L. D. Carlos, M. M. Silva, A. Pawlicka, Mater. Sci. Eng., B 2012, 177, 488.

[13] G. Ribeiro, M. Conde, J. Carvalho, L. C. Rodrigues, R. Alves, R. A. S. Ferreira, A. Pawlicka, L. D. Carlos, M. M. Silva, Mol. Cryst. Liq. Cryst. 2012, 562, 147.

[14] A. Pawlicka, R. I. Mattos, J. F. Lima, C. E. Tambelli, C. J. Magon, J. P. Donoso, Electrochim. Acta 2011, 57, 187.

[15] B. Chatterjee, N. Kulshrestha, P. N. Gupta, Measurement 2016, 82, 490.

[16] L. V. S. Lopes, G. O. Machado, A. Pawlicka, J. P. Donoso, Electrochim. Acta 2005, 50, 3978.

[17] S. C. Barros, A. A. da Silva, D. B. Costa, C. M. Costa, S. LancerosMéndez, M. N. T. Maciavello, J. L. G. Ribelles, F. Sentanin, A. Pawlicka, M. M. Silva, Cellulose 2015, 22, 1911.

[18] P. Mukoma, B. R. Jooste, H. C. M. Vosloo, J. Power Sources 2004, 136, 16.

[19] R. Alves, A. S. S. de Camargo, A. Pawlicka, M. M. Silva, J. Rare Earths 2016, 34, 661.

[20] J. Ma, Y. Sahai, Carbohydr. Polym. 2013, 92, 955.

[21] N. Li, R. Bai, AlChE Annual Meeting, Conference Proceedings, 2004, 5295.

[22] A. Pawlicka, J. P. Donoso, Polymer Electrolytes, Elsevier, New York 2010, pp. 95-128.

[23] S. C. Barros, A. A. da Silva, D. B. Costa, I. Cesarino, C. M. Costa, S. Lanceros-Méndez, A. Pawlicka, M. M. Silva, Cellulose 2014, 21, 4531.

[24] Y. Wan, K. A. M. Creber, B. Peppley, V. T. Bui, Polymer 2003, 44, 1057.

[25] S. Ramesh, R. Shanti, E. Morris, Solid State Sci. 2012, 14, 182.

[26] N. S. Rani, J. Sannappa, T. Demappa, Mahadevaiah, lonics 2015, 21, 133.

[27] N. S. Rani, J. Sannappa, T. Demappa, Mahadevaiah, AIP Conf. Proc. 2013, 1512, 544.

[28] J. P. Esquivel, P. Alday, O. A. Ibrahim, B. Fernández, E. Kjeang, N. Sabaté, Adv. Energy Mater. 2017, 7, 1700275.

[29] D. K. Pradhan, R. N. P. Choudhary, B. K. Samantaray, Int. J. Electrochem. Sci. 2008, 3, 597.

[30] L. S. Ng, A. A. Mohamad, J. Power Sources 2006, 163, 382.

[31] D. F. Vieira, A. Pawlicka, Electrochim. Acta 2010, 55, 1489.

[32] R. Alves, M. M. Silva, Mol. Cryst. Liq. Cryst. 2014, 591, 64.

[33] T. Wang, L. Chen, T. Shen, D. Wu, Int. J. Biol. Macromol. 2016, 93, 775 .

[34] S. C. Barros, M. M. Silva, Cellulose 2018, 25, 3163.

[35] T. D. O. Gadim, A. G. P. R. Figueiredo, N. C. Rosero-Navarro, C. Vilela, J. F. Gamelas, A. Barros-Timmons, C. P. Neto, A. J. D. Silvestre, C. S. R. Freire, F. M. L. Figueiredo, ACS Appl. Mater. Interfaces 2014, 6, 7864.

[36] N. A. Aziz, S. R. Majid, A. K. Arof, J. Non-Cryst. Solids 2012, 358, 1581.

[37] S. Tang, A. Babai, A.-V. Mudring, Angew. Chem., Int. Ed. 2008, 47, 7631.

[38] O. A. Ibrahim, P. Alday, N. Sabaté, J. P. Esquivel, E. Kjeang, J. Electrochem. Soc. 2017, 164, A2448.

[39] L. del T. Román, M. Navarro, G. Hughes, J. P. Esquivel, R. D. Milton, S. D. Minteer, N. Sabaté, Electrochim. Acta 2018, 282, 336. 